\title{
NEPHROTOXICITY INDUCED BY LINEZOLID AND VANCOMYCIN ON ADULT ALBINO RAT: COMPARATIVE EXPEREIMENTAL STUDY
}

\author{
Rabab Fawzy Hindawy ${ }^{1}$ and Fatma Fawzi Hendawy ${ }^{2}$ \\ Forensic Medicine \& Clinical Toxicology Department ${ }^{1}$, and Pharmacology \\ Department ${ }^{2}$, Faculty of Medicine, Benha University, Egypt.
}

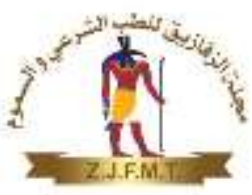

\section{ABSTRACT}

Background: Vancomycin-induced nephrotoxicity is characterized by acute tubular necrosis (ATN) or interstitial damage (ATIN). Vancomycin-resistance among Enterococci has been escalating in recent years in many countries. Linezolid (LNZ), an oxazolidinone is one of the novel drugs that promised effective therapy of infections caused by vancomycin-resistant Enterococci (VRE). Objectives: The present work aimed to experimentally compare the nephrotoxicity induced by linezolid and vancomycin (VCM) on adult albino rat both biochemically and histopathologically. Methodology: Thirty rats were randomly divided into three groups (10 rats each) Group (I) Control group, Group (II) LNZ group and Group (III) VCM group. To study the toxic effect of linezolid on the kidney in comparison with vancomycin. The level of serum creatinine, urea and malondialdehyde (MDA) were measured. Results: It was found in this study that VCM significantly increase serum creatinine, urea and MDA concentrations compared to the control group, and LNZ insignificantly increase serum creatinine, urea and MDA compared to the control group, with no significant difference between the effects of two drugs. Histopathological study of VCM-treated rat kidney showed marked interstitial nephritis with tubular necrosis and desquamation of tubular epithelial cells. Conclusion and Recommendations: Nephrotoxicity in linezolid-treated rats was less than vancomycin-treated rats. Further studies are needed about effect of linezolid on kidney.

Keywords: vancomycin, linezolid, rats, nephrotoxicity.

Corresponding author: Rabab Fawzy Hindawy (dr_rababhindawi@yahoo.com)

\section{INTRODUCTION}

$\mathbf{T}$ The rapid progression and high mortality associated with methicillin-resistant staphylococcal aureus (MRSA) infections and enterococci is a real clinical problem and compels physicians to find a bactericidal solution. Among options, vancomycin and linezolid seem to offer this solution (BarcelóVidal et al, 2018). Vancomycin is a timedependent antibiotic with bactericidal activity useful for treating patients with infections caused by Gram-positive microorganisms, including methicillin-resistant Staphylococcus aureus (Barceló-Vidal et al, 2018).Regarding the nephrotoxicity of vancomycin have accumulated in the literature in the last few decades (Filippone et al, 2017). These toxicities are related to long periods of treatment, concomitant nephrotoxic agents, high dosages, and high vancomycin plasma trough levels (Rybak et al, 2009). Vancomycin-induced nephrotoxicity is characterized by acute tubular necrosis (ATN) or interstitial damage (ATIN), yet the majority of biopsy reports have described (ATIN) rather than ATN (BarcelóVidal et al, 2018). Vancomycin-resistance among Enterococci has been escalating in recent years in many countries. Linezolid, an oxazolidinone is one of the novel drugs that promised effective therapy of infections caused by vancomycin-resistant Enterococci (VRE) (Hussain et al., 2018). The present work aimed to experimentally compare the nephrotoxicity induced by linezolid and vancomycin on adult albino rat both biochemically and histopathologically. The present work aimed to compare nephrotoxicity induced by linezolid and vancomycin on adult albino rat.
II. MATERIALS AND METHODS
II.1 Drugs and chemicals:
Linezolid plastic infusion bag 300ml (600 mg) (Zyvox) [Pfizer Inc, New York, NY, USA]. 
Vancomycin vial $1000 \mathrm{mg}$ (Merck \& Co. Inc, USA). Hematoxylin \& eosin stain [Biostain ready reagents, UK]. Formalin (solution) (neutral $10 \%$ formalin): El-Gomhoria Pharmaceutical Chemical Co., ARE.

\subsection{Preparation of Vancomycin vial 1000 mg}

We added $20 \mathrm{~mL}$ of sterile water (SWI) to $1 \mathrm{~g}$ vial to yield $50 \mathrm{mg} / \mathrm{mL}$ solution; further dilution is required. We diluted $1 \mathrm{~g}$ with $80 \mathrm{~mL}$ of diluent $5 \%$ dextrose in water (D5W). When reconstituted lyophilized powder with diluent for injection, a concentration of $10 \mathrm{mg} / \mathrm{mL}$ for 1 $\mathrm{g}$ vial produced.

\section{II.3. Experimental animals:}

30 adult male albino rats (brought from Experimental Animal Breeding Farm, HelwanCairo) weighing 150-200gm., were used. They have acclimatized for one week and were caged (5/cage) in fully ventilated room (at room temperature) with a 12 hours light/12 hours dark cycle in Anatomy department, Benha faculty of medicine. This study was approved by the local Ethical Committee, Benha Faculty of Medicine.

\section{II.4. Experimental Protocol:}

After one week of acclimatization, rats were randomly divided into three groups (10 rats each) to study the toxic effect of linezolid (LNZ) on the kidney in comparison with vancomycin (VCM).

\section{II.4.1. Groups}

Group (I) Control group: the rats of this group were subdivided into two subgroups (5 rats each):

Subgroup Ia (-ve control): Each animal left without intervention to measure the basic parameters, free access to food and distilled water was allowed for 7 days.

Subgroup Ib (+ve control) (solvent control): Each animal was given solvent (D5W) by intraperitoneal injection twice a day for 7 days

Group (II) LNZ group: the rats of this group were given linezolid $(50 \mathrm{mg} / \mathrm{kg})$ by intraperitoneal injection twice a day for 7 days. This rat dose of LNZ was calculated based on body surface area (Anroop and Shery, 2016) 50 $\mathrm{mg} / \mathrm{kg}$ is animal equivalent dose to human therapeutic dose $600 \mathrm{mg}$.

Group (III) VCM group: rats were given VCM $(200 \mathrm{mg} / \mathrm{kg}$ ) by intraperitoneal (I.P) injection twice a day for 7 days. This dose of VCM was selected based on previous studies (Basarslan et al, 2012; Konishi et al, 2013 and Karami et al, 2018).

II.4.2. Biochemical examination: blood samples were obtained from rats by puncture of the retrobulbar sinus (Schemer, 1967). Serum was prepared by immediate centrifugation then separated to assay the level of serum creatinine, serum urea and oxidative stress indices: level of serum malondialdehyde (MDA).

II.4.3. Histopathological examination: After collecting the blood specimens the rats were sacrificed by diethyl ether, the abdomen was opened, and the kidney was cut. The kidney was cleaned from surrounding tissues and fat then fixed in $10 \%$ phosphate buffered formalin. Fixed specimens were prepared for paraffin sections and staining with hematoxylin \& eosin according to (Dury and Wallington, 1967).

\section{II.4.4. Statistical Analysis}

Software (SPSS, Version 20.0 for Windows, SPSS Inc, Chicago, IL) was used for analyses of the data. Mean and standard error of the mean ( $\mathrm{M} \pm \mathrm{SE}$ ) were used to summarize data. Analysis of variance (ANOVA) ( $\mathrm{F}$ test) was used for multiple comparisons of quantitative variables after establishing their normal distribution. Post hoc test (LSD) was used for multiple comparisons of quantitative variables. Differences were considered significant at $\mathrm{P} \leq 0$ .05 and non-significant at $\mathrm{P}>0.05$.

\section{RESULTS}

\section{III.1. Biochemical study:}

In the present work negative control, and positive control (solvent) groups, showed a non-significant difference $(\mathrm{p}>0.05)$ as regard biochemical parameters (serum urea, creatinine and MAD). So, the mean of all control groups was chosen as a representative group for the two control groups to be compared with the results of the treated groups. 
Effect of Linezolid and Vancomycin on Serum Urea of Rats:

Intraperitoneal injection of linezolid (LNZ) $(50 \mathrm{mg} / \mathrm{kg})$ twice a day for 7 days resulted in nonsignificant rise of serum urea $(\mathrm{P}>0.05)$ from $41.66 \pm 3.05$ in control group (group I) to $61.166 \pm 5.58$ in LNZ group (group II). Intraperitoneal injection of vancomycin (VCM)
$(200 \mathrm{mg} / \mathrm{kg})$ twice a day for 7 days resulted in significant rise of serum urea $(\mathrm{P}<0.05)$ from $41.66 \pm 3.05$ in control group (group I) to 78.5 \pm 6.39 in VCM group (group III). Comparing the result of LNZ-treated group (group II) to that of VCM-treated group (group III), there was nonsignificant differences $(\mathrm{P}>0.05)$ between LNZ and VCM on serum urea.

Table (1): Comparison between the Studied Groups of Rats Regarding Serum Urea

\begin{tabular}{|c|c|c|l|l|}
\hline $\begin{array}{l}\text { Serum } \\
\text { urea }\end{array}$ & $\begin{array}{c}\text { Control } \\
\text { group }\end{array}$ & $\begin{array}{c}\text { Linezolid- } \\
\text { treated } \\
\text { group }\end{array}$ & $\begin{array}{l}\text { Vancomycin-treated } \\
\text { group }\end{array}$ & P \\
\hline$(\mathbf{M} \pm \mathbf{S E})$ & $41.66 \pm 3.05$ & $\begin{array}{c}61.166 \pm \\
5.58^{\#}\end{array}$ & $78.5 \pm 6.39^{*}$ & $<0.05$ \\
\hline
\end{tabular}

*Significant $(\mathrm{p}<0.05)$ compared to control group

\#Nonsignificant ( $p>0.05)$ compared to control group and vancomycin-treated group

Effect of Linezolid and Vancomycin on Serum Creatinine of Rats:

Intraperitoneal injection of $\mathrm{LNZ}(50 \mathrm{mg} / \mathrm{kg})$ twice a day for 7 days resulted in nonsignificant rise of serum creatinine $(\mathrm{P}>0.05)$ from $0.533 \pm$ 0.033 in control group (group I) to $0.75 \pm 0.047$ in LNZ group (group II). Intraperitoneal injection of VCM $(200 \mathrm{mg} / \mathrm{kg})$ twice a day for 7 days resulted in significant rise of serum creatinine $(\mathrm{P}<0.05)$ from $0.533 \pm 0.033$ in control group (group I) to $0.966 \pm 0.095$ in VCM group (group III). Comparing the result of LNZ-treated group (group II) to that of VCM-treated group (group III), there was nonsignificant differences $(\mathrm{P}>0.05)$ between LNZ and VCM in their effect on serum creatinine.

Table (2): Comparison between the Studied Groups of Rats Regarding Serum Creatinine

\begin{tabular}{|c|c|c|c|c|}
\hline $\begin{array}{l}\text { Serum } \\
\text { creatinine }\end{array}$ & $\begin{array}{c}\text { Control } \\
\text { group }\end{array}$ & $\begin{array}{c}\text { Linezolid- } \\
\text { treated group }\end{array}$ & $\begin{array}{c}\text { Vancomycin- } \\
\text { treated group }\end{array}$ & $\mathbf{P}$ \\
\hline$(\mathbf{M} \pm \mathbf{S E})$ & $0.533 \pm 0.033$ & $0.75 \pm 0.047 \#$ & $0.966 \pm 0.095 *$ & $<0.05$ \\
\hline
\end{tabular}

*Significant $(\mathrm{p}<0.05)$ compared to control group

\#Nonsignificant $(\mathrm{p}>0.05)$ compared to control group and vancomycin-treated group 
Effect of Linezolid and Vancomycin on Oxidative Activity (Malondialdehyde) of Rats:

Intraperitoneal injection of linezolid $(50 \mathrm{mg} / \mathrm{kg})$ twice a day for 7 days resulted in nonsignificant rise of serum malondialdehyde (MDA) (P $>0.05$ ) from $3 \pm 0.096$ in control group (group I) to $4.5 \pm 0.45$ in LNZ group (group II). Intraperitoneal injection of VCM $(200 \mathrm{mg} / \mathrm{kg})$ twice a day for 7 days resulted in significant rise of serum MDA $(\mathrm{P}<0.05)$ from $3 \pm 0.096$ in control group (group I) to $5.85 \pm 0.62$ in VCM group (group III). Comparing the result of LNZ-treated group (group II) to that of VCM-treated group (group III), there was nonsignificant differences $(\mathrm{P}>0.05)$ between LNZ and VCM in their effect on MDA.

Table (3): Comparison between the Studied Groups of Rats Regarding Serum MDA

\begin{tabular}{|c|c|c|c|c|}
\hline MDA & $\begin{array}{c}\text { Control } \\
\text { group }\end{array}$ & $\begin{array}{c}\text { Linezolid- } \\
\text { treated group }\end{array}$ & $\begin{array}{c}\text { Vancomycin- } \\
\text { treated group }\end{array}$ & $\mathbf{P}$ \\
\hline$(\mathbf{M} \pm \mathbf{S E})$ & $3 \pm 0.096$ & $4.5 \pm 0.45 \#$ & $5.85 \pm 0.62^{*}$ & $<0.05$ \\
\hline
\end{tabular}

*Significant $(\mathrm{p}<0.05)$ compared to control group

\#Nonsignificant $(\mathrm{p}>0.05)$ compared to control group and vancomycin-treated group

MDA: Malondialdehyde

III .2 Histopathological study:

Histological examination of a cut section of the kidney of control group (group I) showed that normal collecting tubules lined by one layer of cuboidal epithelial cells, normal proximal convoluted tubules and normal distal convoluted tubules. In linezolid-treated group (group II), a cut section of the kidney showed cloudy swelling of tubular epithelium with mild interstitial nephritis. In vancomycin group (group III), there was accumulation of inflammatory cells in interstitial tissue which indicates marked interstitial nephritis with tubular necrosis and desquamation of tubular epithelial cells.

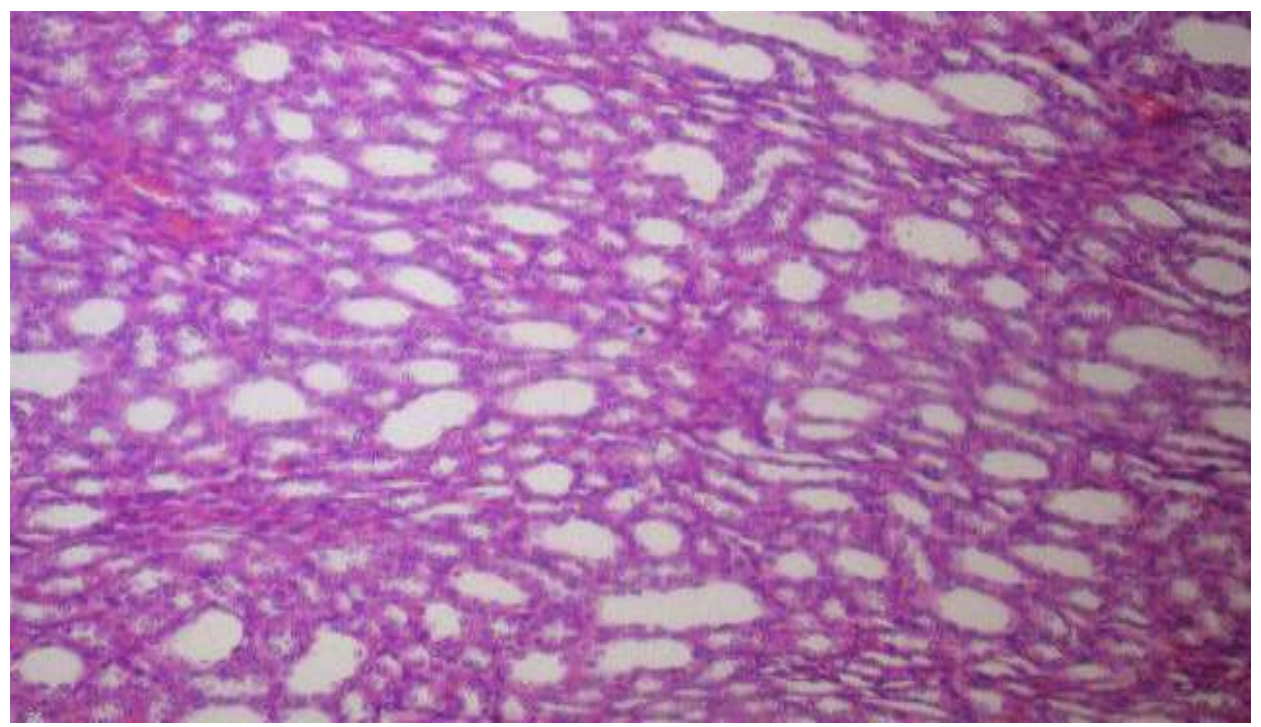

Figure (1) A photomicrograph of a cut section in the kidney of a control rat (group I) showing normal renal tubules lined by one layer of cuboidal epithelial cells. (H\&E×200). 


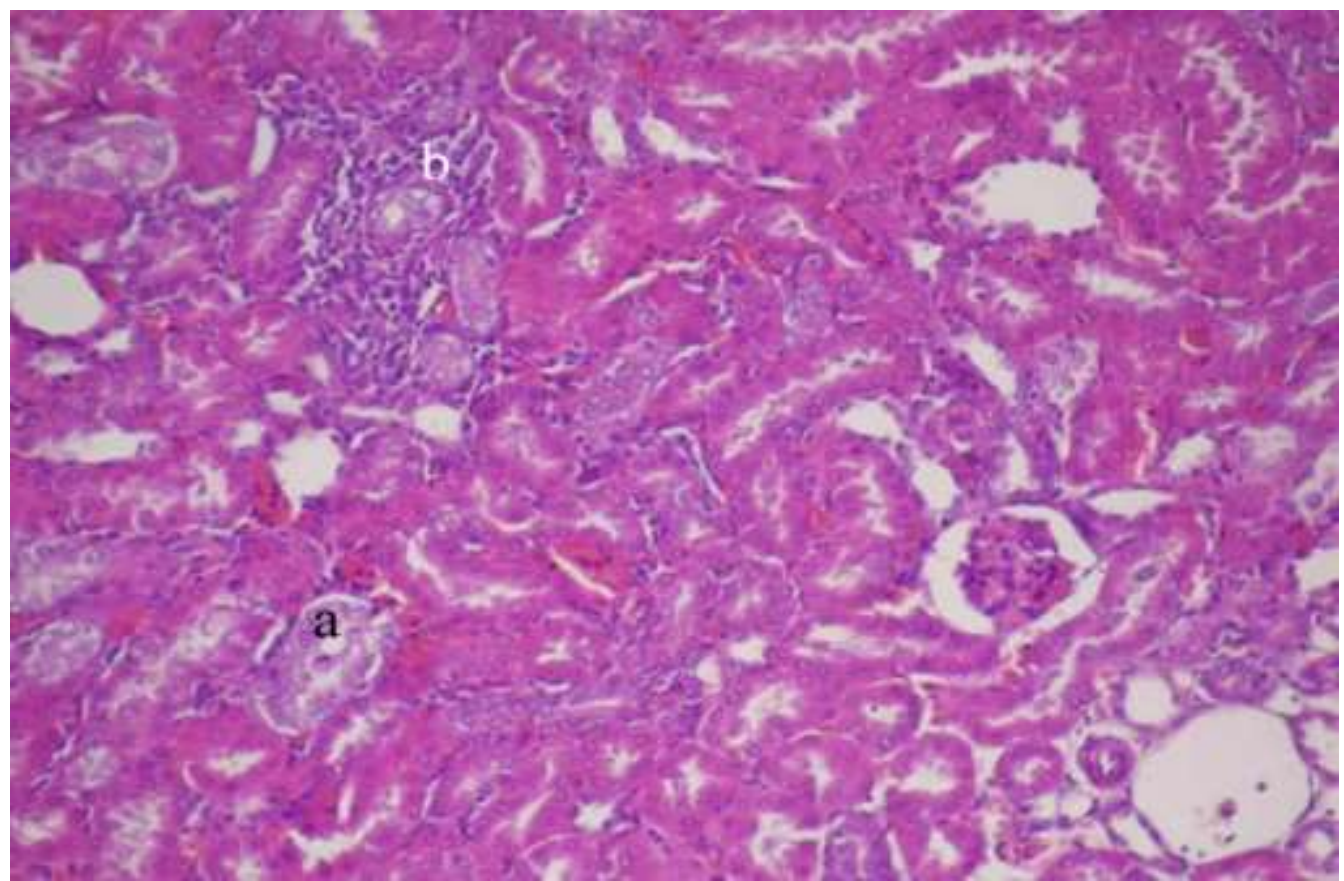

Figure (2) A photomicrograph of a cut section in the kidney of linezolid-treated rat (group II) showing

(a) cloudy swelling of tubular epithelial cells with (b) mild interstitial nephritis. (H\&E×200).

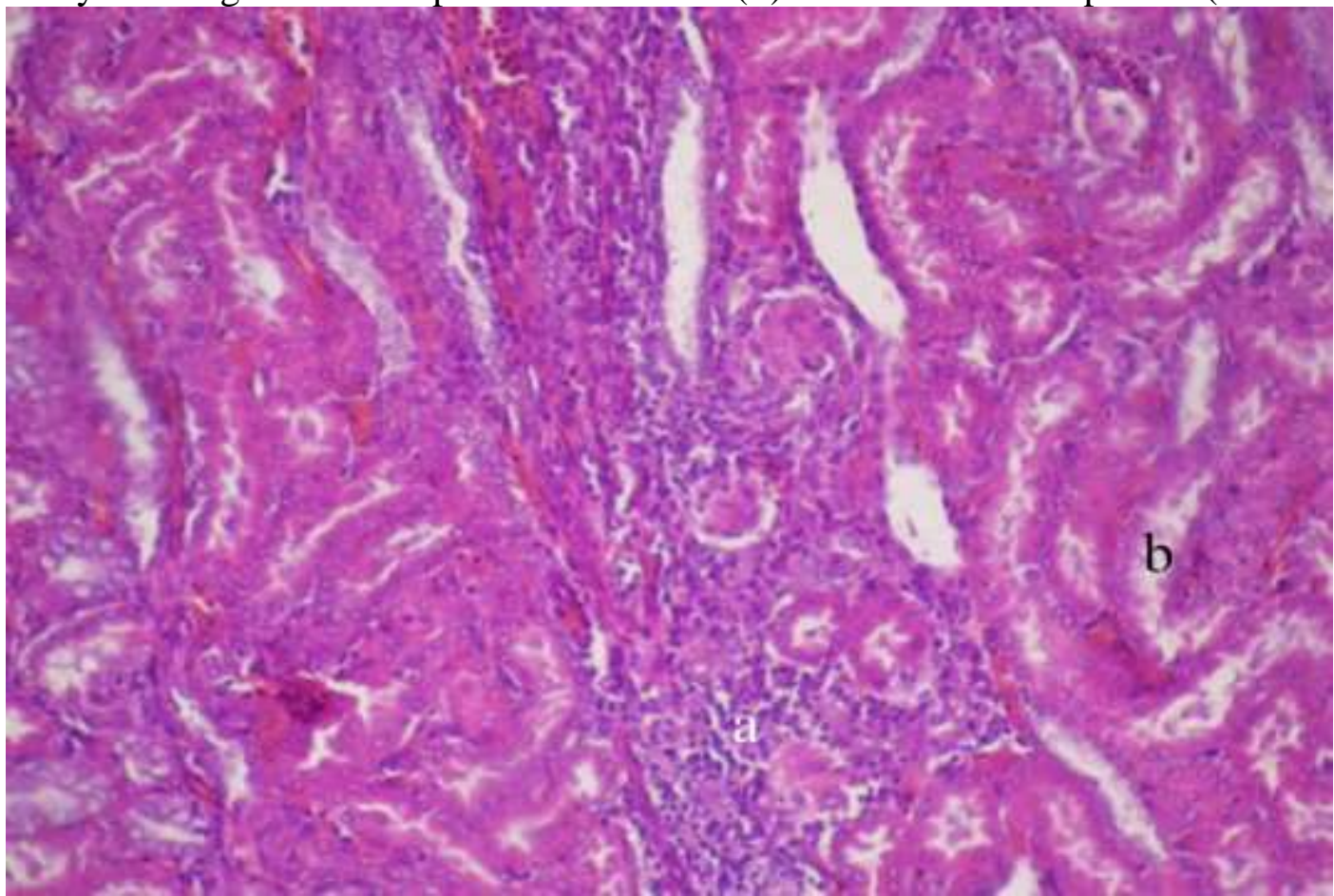

Figure (3) A photomicrograph of a cut section in the kidney of vancomycin group (group III) showing (a) marked interstitial nephritis with (b) tubular necrosis and desquamation of tubular epithelial cells. (H\&E×200).

\section{DISCUSSION}

Vancomycin (VCM) hydrochloride is a glycopeptide antibiotic which inhibits the biosynthesis of bacterial cell wall peptidoglycan polymer. It is an important antibiotic for treating resistant infections such as methicillin-resistant S. aureus (MRSA) infections (Karami et al, 2018). Nephrotoxicity is one of the major adverse effects of this drug, which limits the drug dose and duration of 
administration (Elyasi et al, 2012). Park et al (2018) suggested a few risk factors of vancomycin-associated nephrotoxicity, including high dose, old age, long duration of therapy, and concomitant nephrotoxic agents. Vancomycin-resistance among Enterococci has been reported in last years in many countries. Linezolid, an oxazolidinone, is one of the new drugs that promised effective therapy against infections caused by vancomycin-resistant Enterococci (Hussain et al, 2018). Chavanet P. (2013) found that LNZ was better than VCM for the treatment of MRSA nosocomial pneumonia when a prospective randomized study was made comparing a fixed linezolid dose to dose-optimized vancomycin for the treatment of MRSA nosocomial pneumonia. Linezolid is a mostly safe antibiotic, when taken for short periods (Marino and Sutin, 2007). Usage of linezolid for long duration has been associated with bone marrow suppression (Falagas et al, 2008),lactic acidosis (Barnhill et al, 2012) and it may be the cause of nerve damage, including may be irreversible optic nerve damage (Saijo et al, 2005). There are also postmarketing reports of seizures, Bell's palsy and kidney toxicity (Metaxas and Falagas 2009). In this study we compare between nephrotoxic effect of linezolid and vancomycin in adult albino rats. In the present study, repeated i.p. administration of $200 \mathrm{mg} / \mathrm{kg}$ VCM, for 7 consecutive days to rats, induced a considerable raise in serum creatinine and urea concentrations compared to the control group, suggesting an acute renal failure. These findings are in agreement with the results of other experimentally studies about the nephrotoxicity of VCM (Basarslan et al, 2012; Elyasi et al, 2013 and Konishi et al, 2013). In the present study, repeated i.p. administration of $50 \mathrm{mg} / \mathrm{kg} \mathrm{LNZ}$, for 7 consecutive days to rats, induced a considerable insignificant raise in serum creatinine and urea concentrations compared to the control group. Esposito et al (2007) reported the first case of linezolidrelated acute renal failure in a patient with kidney transplantation. There was increase in serum creatinine 136- 221 micromole/l, with mild hypereosinophilia, anemia and thrombocytopenia, 8 days after starting linezolid therapy. A case of an old female who was treated for prosthetic joint infection and (MRSA) bacteremia with vancomycin followed by linezolid intake. On the seven day of linezolid therapy, the patient had severe pruritus, macular rash, facial edema, eosinophilia, high increase in serum creatinine level, and mild hepatitis (Sébastien et al, 2009). Sébastien et al (2009) also found rapid improvement of renal function was due to discontinuation of linezolid and a short term treatment of prednisone. The present study found that VCM significantly increases serum MDA compared to the control group while LNZ increases serum MDA insignificantly, with no significant difference between the effect of two drugs. Although the mechanism of renal toxicity from vancomycin is not fully known, experimental studies maintained proinflammatory oxidation, mitochondrial dysfunction and cellular apoptosis as the principal causes of injury (Oluwatoyin, 2016). Oxidative phosphorylation caused by vancomycin induces free oxygen radicals and so reduces the activity of defensive antioxidative enzymes such as superoxide dismutase and catalases (Oktem et al, 2005). Ocak et al (2007) found that antioxidative biological agents that successfully used in animal studies as vitamin $\mathrm{E}$, vitamin $\mathrm{C}, \mathrm{N}$ acetylcysteine, caffeic acid and phenethyl ester had a protection against vancomycin induced renal damage. Rajitha et al (2011) reported that lipid peroxidation products as MDA was markedly increased by vancomycin. Ahmida (2012) added that the antioxidant curcumin has beneficial effects and could be able to antagonize vancomycin nephrotoxicity by ameliorating reduction in the activities of antioxidant enzymes, [superoxide dismutase (SOD), catalase (CAT), and glutathione peroxidase (GSH-Px)] in plasma and kidney tissue which induced by vancomyin. Tianlin et al (2014) reported a decrease of hemocyte level 
and enzymatic activities of superoxide dismutase (SOD) and catalase in rat serum induced by linezolid in a dose-dependent manner. While the amount of MDA and nitric oxide (NO) were increased in rats' serum, the above changes could partially be reversed by vitamin E supplementation. Wang et al (2016) found that the oxidative stress markers, [reactive oxygen species (ROS), malondialdehyde (MDA)], that increased in LNZ-induced thrombocytopenia, suggesting oxidative damage as may be the underlying mechanism. Laura et al (2017) added that the oxidative phosphorylation system capacity was decreased by linezolid at therapeutic concentrations. In this study histological observation confirms the biochemical result. Histopathological study of VCM-treated rat kidney showed accumulation of inflammatory cells in interstitial tissue which indicates marked interstitial nephritis with tubular necrosis and desquamation of tubular epithelial cells. The histological findings on the majority of studies of vancomycin-induced nephrotoxicity are acute interstitial nephritis (Plakogiannis and Nogid, 2007) and rarely acute tubular necrosis (Wu et al, 2007). Rajitha et al (2011) found that renal histopathology of vancomycin treated rats showed marked glomerular and tubular damages; which is attenuated by treatment with atorvastatin. Histopathological study of LNZ -treated rat kidney showed cloudy swelling of tubular epithelium with mild interstitial nephritis. Esposito et al (2007) reported that the transplant kidney biopsy, performed 15 days from the start of linezolid therapy, in a case of linezolid-related acute renal failure in a kidneytransplant patient, showed interstitial nephritis and focal tubular atrophy. A case of an old diabetic man with alcoholic cirrhosis admitted in ICU. On the third day of linezolid treatment, there were severe pruritus, macular rash, eosinophilia, and renal dysfunction. Renal biopsy showed acute tubulointerstitial nephritis (Nayak et al, 2012). Hector et al (2007) reported that seven days after beginning linezolid therapy in a 30-year-old healthy man with tibial osteomyelitis. There were development of a diffuse maculopapular rash and acute renal failure. Acute interstitial nephritis is diagnosed by renal biopsy.

V. Conclusion and Recommendations:

Renal toxicity is one of the most important side effects of VCM; therefore their clinical uses are limited. In our study, we found that nephrotoxicity in linezolid-treated rats less than in vancomycin-treated rats.

Because of side effects of linezolid, i.e. nephrotoxicity, we recommend close monitoring of kidney function tests when linezolid therapy is attempted. Clinicians should be aware of these potential lifethreatening adverse reactions and monitor kidney function while patients are using linezolid. Further studies are needed about the effect of linezolid on kidney.

\section{ACKNOWLEDGEMENT}

Our deep appreciation to the staff members of Forensic Medicine \& Clinical Toxicology; Pharmacology, Anatomy and Pathology Departments, Faculty of Medicine, Banha University, for their cooperation. http://www.fmed.bu.edu.eg.

\section{REFERENCES}

1. Ahmida HS (2012): Protective role of curcumin in nephrotoxic oxidative damage induced by vancomycin in rats. Experimental and Toxicologic Pathology; 64(3): 149-153.

2. Anroop BN and Jacob S (2016): A simple practice guide for dose conversion between animals and human. J Basic Clin Pharm. March -May 2016; 7(2): 27-31

3. Bamgbola O (2016): Review of vancomycininduced renal toxicity: an update. Ther Adv Endocrinol Metab. Jun; 7(3): 136-147.

4. Barceló-Vidal J, Rodríguez-García E and Grau S (2018): Extremely high levels of vancomycin can cause severe renal toxicity, Infection and Drug Resistance, 11: 1027-1030.

5. Barnhill AE, Brewer MT and Carlson SA (2012): "Adverse effects of antimicrobials via predictable or idiosyncratic inhibition of host mitochondrial components". Antimicrobial Agents and Chemotherapy. 56 (8): 4046-4051. 
6. Basarslan F, Yilmaz N and Ates S et al (2012): Protective effects of thymoquinone on vancomycininduced nephrotoxicity in rats. Hum Exp Toxicol.; 31(7):726-733.

7. Bonilla H, Rich M and et al (2009): LinezolidInduced Acute Interstitial Nephritis. Infect Dis Clin Pract. 43: 11-12

8. Chavanet P. (2013): Médecine et Maladies Infectieuses;43: 451-455

9. Dury RAB and Wallington EA (1967): Carleton Histological Technique; $4^{\text {th }}$ ed. Oxford University Press, Oxford, P. 129.

10. Elyasi S, Khalili $\mathrm{H}$ and Dashti-Khavidaki $\mathrm{S}$ et al (2012): Vancomycin-induced nephrotoxicity: mechanism, incidence, risk factors and special populations. A literature review. Eur J Clin Pharmacol.; 68(9):1243-1255.

11. Elyasi S, Khalili H and Hatamkhani S et al (2013): Prevention of vancomycin induced nephrotoxicity: a review of preclinical data. Eur J Clin Pharmacol.; 69(4):747-754.

12. Esposito L, Kamar $\mathrm{N}$ and Guilbeau-Frugier $\mathrm{C}$ et al (2007): Linezolid-induced interstitial nephritis in a kidney-transplant patient. Clinical nephrology; 68(5):327-329 .

13. Falagas ME, Siempos II and Vardakas KZ (2008): "Linezolid versus glycopeptide or beta-lactam for treatment of Gram-positive bacterial infections: meta-analysis of randomised controlled trials". Lancet Infectious Diseases. 8 (1): 53-66.

14. Filippone EJ, Kraft WK and Farber JL (2017): The Nephrotoxicity of Vancomycin. Clin Pharmacol Ther; 102(3):459-469.

15. Hussain MS, Sattar A and Hussain M (2018): In vitro efficacy of linezolid against vancomycin resistant Enterococci. Pak J Pharm Sci. Sep; 31(5):1853-1857.

16. Karami M, Mostafazadeh $M$ and Sadeghi $H$ et al (2018): Nephroprotective Effect of Nasturtium officinale (Watercress) Ethanol Extract and Vitamin E on Vancomycin-Induced Nephrotoxicity in Rats. Jundishapur J Nat Pharm Prod. ; 13(1):e671-78

17. Konishi H, Morita Y and Mizumura M et al (2013): Difference in nephrotoxicity of vancomycin administered once daily and twice daily in rats. J Chemother; 25(5):273-278.

18. Liobet L, PilarBayona-Bafaluy $\mathrm{M}$ and PacheuGraud D et al (2017): Pharmacologic concentrations of linezolid modify oxidative phosphorylation function and adipocyte secretome. Redox Biology; 13: 244-254.
19. Marino PL and Sutin KM (2007): "Antimicrobial therapy". The ICU book. Hagerstown, MD: Lippincott Williams \& Wilkins. p. 817.

20. Metaxas EI and Falagas ME (2009): "Update on the safety of linezolid". Expert Opinion on Drug Safety. 8 (4): 485-491.

21. Nayak S, Rastogi A and Vibhanshu Gupta et al (2012): Acute interstitial nephritis and drug rash with secondary to Linezolid. Indian $\mathrm{J}$ Nephrol. 22(5): 367-369.

22. Ocak S, Gorur S and Hakverdi S et al (2007): Protective effects of caffeic acid phenethyl ester, vitamin $\mathrm{C}$, vitamin $\mathrm{E}$ and $\mathrm{N}$-acetylcysteine on vancomycin-induced nephrotoxicity in rats. Basic Clin Pharmacol Toxicol 100: 328-333.

23. Oktem F, Arslan M and Ozguner F et al. (2005): In vivo evidences suggesting the role of oxidative stress in pathogenesis of vancomycin-induced nephrotoxicity: protection by erdosteine. Toxicology 215: 227-233.

24. Panonnummal R, VarkeyJ and Dinoop D R (2011): Protective effect of atorvastatin against vancomycin induced nephrotoxicity in albino rats. Pharmacie Globale; 2(8):76-81.

25. Park SJ, Lim NR and Park HJ et al. (2018): Evaluation of risk factors for vancomycin-induced nephrotoxicity. Int J Clin Pharm. 40:112-118.

26. Plakogiannis R and Nogid A (2007): acute interstitial nephritis associated with coadministration of vancomycin and ceftriaxone: case series and review of the literature. Pharmacotherapy 27: 1456-1461.

27. Rybak M, Lomaestro B and Rotschafer JC et al. (2009): Therapeutic Monitoring of Vancomycin in Adult Patients: A Consensus Review of the American Society of Health-System Pharmacists, the Infectious Diseases Society of America, and the Society of Infectious Diseases Pharmacists. Am J Heal Pharm; 66: 82-98.

28. Saijo T, Hayashi K and Yamada H et al (2005): "Linezolid-induced optic neuropathy". American Journal of Ophthalmology 139 (6): 1114-1116.

29. Savard S, Riope J and Desmeules S et al (2009): Linezolid-Associated Acute Interstitial Nephritis and Drug Rash With Eosinophilia and Systemic Symptoms (DRESS) Syndrome. Am J Kidney Dis. 54(6):e17-e20

30. Schemer A (1967): The blood morphology of laboratory; $3^{\text {rd }}$ ed., Davis F.A. Company, Philadelphia. P.43

31. Wang TL, Guo DH and Bai Y et al (2016): Thrombocytopenia in Patients Receiving Prolonged 
Linezolid May be caused by Oxidative Stress. Clin Drug Investing; 36(1):67-75.

32. Wang T, Guo D and Dong X et al (2014): Effect of linezolid on hematological and oxidative parameters in rats. The Journal of Antibiotics; 67(6)
33. Wu C, Wang J and Chiou Y et al (2007): Biopsy proven acute tubular necrosis associated with vancomycin in a child: case report and literature review. Ren Fail 29: 1059-1061. 
السمية الكلوية لعقاري الفانكومايسين واللاينوزوليد: دراسة مقارنة تجريبية على الجرزان البيضاء البالغة

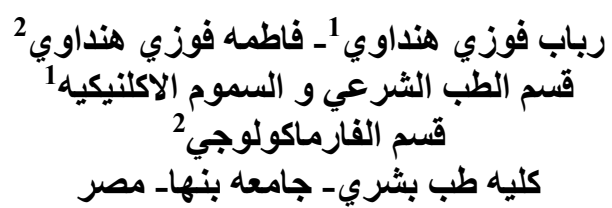

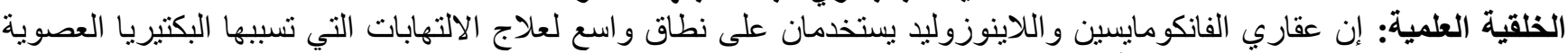

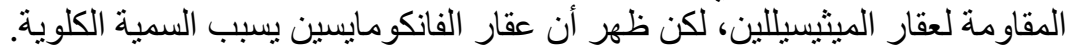

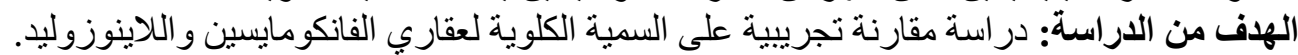

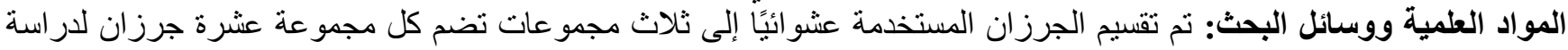

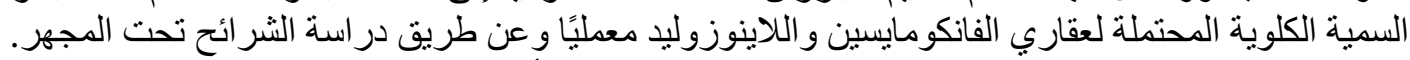

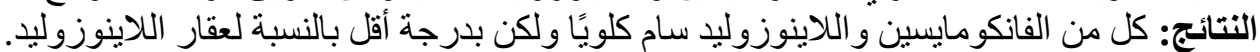

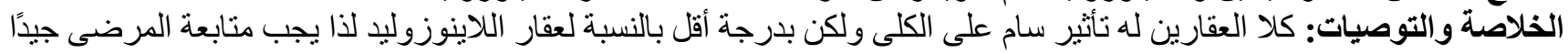
باستخدام تحاليل وظائف الكلى بصورة الكقارين لهورية. 